TÜSİAD-KOÇ UNIVERSITY ECONOMIC RESEARCH FORUM WORKING PAPER SERIES

\title{
DECIDING TO DECIDE: GENDER, LEADERSHIP AND RISK-TAKING IN GROUPS
}

\author{
Seda Ertac \\ Mehmet Y. Gurdal
}

Working Paper 1028

October 2010

TÜSİAD-KOÇ UNIVERSITY ECONOMIC RESEARCH FORUM Rumeli Feneri Yolu 34450 Sariyer/Istanbul 


\title{
Deciding to Decide: Gender, Leadership and Risk-Taking in Groups
}

\author{
Seda Ertac $^{1}$ \\ Koc University \\ Mehmet Y. Gurdal \\ TOBB ETU
}

October 2010

\begin{abstract}
Being the leader in a group often involves making risky decisions that affect the payoffs of all members, and the decision to take this responsibility in a group is endogenous in many contexts. In this paper, we experimentally study: (1) the willingness of men and women to make risky decisions on behalf of a group, (2) the amount of risk men and women take for the group, in comparison to their individual decisions. We observe a striking difference between males and females, with a much lower fraction of women being willing to make the group decision than men. The amount of risk taken for the group is generally lower than in the case where subjects decide for themselves only, indicating a cautious shift. The women that would like to make the group decision and the women that do not are no different in terms of how much risk they take for themselves, nor for their group. For men, on the other hand, we find that the ones who would like to lead tend to take more risk on behalf of the group. We also present several results on the relationship of risk-taking and leadership decisions with personality traits.
\end{abstract}

Keywords: gender, group decision-making, risk, leadership, experiments.

JEL Codes: C91, C92, D81, J16.

\footnotetext{
${ }^{1}$ Corresponding author. Department of Economics, Koc University, Rumeli Feneri Yolu Sariyer, Istanbul 34450 Turkey (email: sertac@ ku. edu.tr). Gurdal: Department of Economics, Tobb ETU, Sogutozu Cad. No. 43 Ankara, 06560 Turkey (email: mygurdal@etu.edu.tr). Seda Ertac thanks the European Union (International Reintegration Grant) for financial support.
} 


\section{Introduction}

Being the leader in a group often involves making risky decisions that affect the payoffs of all members of the group. These types of decisions can range from choosing a restaurant for dinner with your friends to making an investment decision for a fund subject to joint ownership. Who makes such decisions in a group context is usually endogenously determined, with people who are more willing to take the responsibility being more likely to emerge as decision-makers. Yet, cases where one is exogenously appointed to make such decisions are not uncommon either.

In this paper, we study the characteristics that affect a person's willingness to make risky decisions for a group, focusing on gender and individual risk attitudes, as well as personality traits. Our group decision context involves allocating a fixed amount of money between a risky and a riskless option in a setting where all group members earn the same payoff based on a single member's allocation decision. We compare the actual decisions of people who prefer to make this group decision with the decisions of those who would prefer not to, testing whether and how self-selected and appointed "leaders" differ in their risk-taking. ${ }^{2}$

Our main focus among the potential determinants of leadership in group decision-making is gender. Having to make risky decisions that determine others' payoffs is an important aspect of top positions in the workplace as well as in politics, public service and the military, and it is well-known that women occupy such leader positions much less frequently than men, both in the United States and in other developed and developing countries (Eagly and Karau (2002), Adler and Izraeli (1994), Melkas and Anker (1997), Blau, Ferber and Winkler (2002)). Motivated by these facts, our main goal in the paper is to study whether the absence of women from leader positions could arise from self-selection due to different preferences on the part of men and women towards taking responsibility as a decision-maker for others under risk. ${ }^{3}$ In addition, given that women are usually found to be individually more risk-averse than men in experiments (see Croson and Gneezy (2009), Eckel and Grossman (2008), and the references therein), it is natural to conjecture that women's risk-taking for others could be different than men's.

\footnotetext{
${ }^{2}$ We use the term "leader" throughout the paper as a shortcut for "decision-maker for the group". While risky decisions are an important component of executive decision-making and leadership, it is important to recognize that the concept of leadership as a whole extends beyond the aspects that our decision task captures.

${ }^{3}$ Explanations based on the family-career balance, ability differences and discrimination have traditionally been proposed as potential determinants of the documented gender gaps.
} 
Therefore, we also study whether men and women make different decisions in the group context as compared to an individual risk context, and explore whether their decisions correlate with their willingness to be a leader.

Interestingly, the literature that studies risk-taking decisions made on behalf of others, or in groups where members have correlated payoffs is relatively new in experimental economics. One strand of the existing literature contrasts decisions made on behalf of others with individual decisions. For example, Chakravarty et. al. (2005) presents the results of an experiment where individuals decide for themselves and for an anonymous stranger. They find that there is a decline in risk-aversion during decisions made for others. Daruvala (2007) shows that when subjects make choices for others, they use a combination of their own risk preferences and their predictions about the risk preferences of the target group. Both genders predict that women exhibit higher risk-aversion compared to men. Another strand of the literature has considered how groups make risky decisions through deliberation or voting, compared to individuals. Masclet et al. (2009) find that groups are more likely to make safe choices. Baker et al. (2007) find a similar result. Harrison et al. (2005) use majority voting for group decisions and find that social risk, i.e. the risk taken in groups can be closely approximated by individual decisions. Shupp and Williams (2008) show that group discussion yields higher risk-aversion during decisions involving relatively higher risk. ${ }^{4}$

The current paper has connections to both strands of the literature mentioned above. We use the risk allocation task of Gneezy and Potters (1997) to compare individual risk-taking with the risk taken on behalf of a group. Following risky decisions made individually, subjects are placed in a group context where all members earn equal rewards. The decision that a single subject makes for the group determines the payoffs of everyone in the group, including the decider himself/herself. Whose decision gets implemented for the group is determined endogenously. We use a design where everyone makes decisions for the group, but subjects who express a preference for being the group decision-maker have a higher chance for their decisions

\footnotetext{
${ }^{4}$ In contrast to the economics literature, in social psychology there has been a continuous interest in how individuals take risk when placed in groups as compared to individual decisions. Changes in decisions in a group have been termed "choice shifts", with some papers finding evidence for "risky shifts" (higher risk in groups) and some for "cautious shifts" (lower risk in groups), under a variety of group decision-making procedures. For a survey of this literature, see Davis (1992).
} 
to be implemented for the group. This allows us to compare the group decisions of willing and unwilling leaders.

Our main result is that there is a strong gender gap between the willingness of men and women to decide on behalf of the group. While a vast majority of men (86\%) prefer their decisions to be implemented as the group decision, only about half of the women (55\%) express such a preference. Consistently with findings in the experimental economics literature on gender and individual risk-taking, we find that women are more risk-averse than men, in both the individual context and in the group context. Interestingly, however, the risk attitudes of women have no effect on whether they would like to decide for their group or not. In other words, women who take more risk and less risk individually are equally likely to volunteer to be leaders. Moreover, leader and non-leader women also act similarly when put in the position of deciding for the group. In contrast, men who prefer to be the decision-maker for their group are significantly more risk-taking than men who do not, both in the individual and the group decision-making context. Comparing individual and group decisions for all subjects, we find that "cautious shifts" are frequent: for the same set of decision parameters, when the level of risk taken in groups is different than the risk taken individually, the direction of the change indicates an increase in risk aversion during in-group decisions.

The paper also contributes to the recent endeavor of exploring the correlation of economic decisions with personality measures (see Borghans et al. (2008)). In addition to choice data, we also collect data on subjects' personality traits, using a version of the 5-factor (also known as the "Big Five") personality test (Costa and McCrae (1992), adapted by Gulgoz (2002)). We find suggestive evidence that males who like to decide for the group score higher on "openness" and lower on "agreeableness" traits as compared to males who do not, whereas women who take more risk individually tend to be less "neurotic".

The rest of this paper is organized as follows. In section 2, we describe the design and procedures. Section 3 presents the results, and Section 4 includes a discussion and concluding remarks. 


\section{Experimental Design and Procedures}

Our design consists of two parts: individual decision-making and group decision-making. There are 3 decisions in each part. In each decision task, subjects decide how much of 10 Turkish Liras $^{5}$ to allocate to a riskless option and how much of it to allocate to a risky option (as in Gneezy and Potters (1997)). While the amount invested in the riskless option is safe, the amount invested in the risky option is multiplied by a factor $p$ with $50 \%$ chance (where $p>1$ ), and is lost with $50 \%$ chance. Subjects make betting decisions six times, three for themselves alone, and three on behalf of a group of five randomly selected subjects (including themselves). In both the individual and the group decision-making tasks, the probability of the good state, $\mathrm{p}$, takes the values of 1.5, 2 and 2.5.

We use random payment schemes on both decisions and subjects. Subjects are informed that one of the six decisions will be randomly selected at the end of the experiment for payment, and that a number of subjects would be randomly selected to be paid according to their choices in the chosen decision. ${ }^{6}$ If the individual task is chosen for payment, selected subjects are paid on the basis of their own decisions. If the group task is chosen for payment, all of the five selected subjects that form a group get the same payoff. This payoff is based on the decision of a single group member. Before group decision-making starts, each individual is asked whether they would like to be the decision-maker for their group. After this, they are asked to make the three decisions in the betting task (with $\mathrm{p}=1.5,2$ and 2.5) on behalf of the group, to be implemented in case they are chosen as the decision-maker. If more than one person wants to be the decisionmaker, a random draw among those determines whose decision counts as the group decision. If no one wants to be the decision-maker, one of the five people in the group is selected randomly, and his/her decision counts. That is, whether or not someone is willing to make the groupdecision or not, there is always a chance that their decisions could be implemented. This allows us to gather data on the decisions of both subjects who are willing to be the leader, and those who are not.

The experiments were conducted in undergraduate economics classes at two universities in Turkey, Koc University and TOBB ETU, in the spring of 2010. We have data from 128

\footnotetext{
${ }^{5}$ At the time of the experiments, 1 TL corresponded to $\$ 0.62$.

${ }^{6}$ Both within-subject and between-subject random payment schemes are quite commonly used in economics experiments (see Baltussen et al. (2010) for a discussion of the effects of different randomization procedures).
} 
subjects in total (57 subjects from Koc University, 71 from TOBB). 49 subjects were female, whereas 79 subjects were male. The experiment was conducted by pencil-and-paper. Subjects were randomly assigned a unique ID number, which identified them throughout the experiment. All subjects were paid a show-up fee of 5 Turkish Liras. In addition, one in 5 subjects on average were randomly selected and paid for their decisions. ${ }^{7}$ After subjects made the three individual choices, they were asked to make (1) the leadership decision, (2) the three risk decisions for the group, in case they are selected to be the leader for their group. Subjects never learned who was in their group. After all the decisions were made, one of the six decisions was randomly chosen (by a die cast by a volunteer subject) to be paid. If the decision to be compensated was a group decision, then all five members that formed the selected group(s) were paid the same amount of money, based on that group's leader's decision.

After the experiment, subjects were presented with the Neo-FF-TR Personality Survey (Gulgoz (2002)), which rates individuals on 5 personality traits: openness, conscientiousness, extroversion, agreeableness, and neuroticism.

\section{Results}

\subsection{Individual Risk Decisions}

We first present results from the individual risk decisions. Table 1 reports summary statistics on the amount of risk taken by males and females in the individual decision-making task. We find that women are generally more risk-averse than men: men allocate more money to the risky option than women, and the difference is statistically significant for $\mathrm{p}=2$ and $\mathrm{p}=2.5$ ( $\mathrm{p}$ values $=0.004$ and 0.0001, respectively, in Mann-Whitney tests).

\section{< Insert Table 1 about here >}

\footnotetext{
${ }^{7}$ Since we conducted the experiment at the end of classes with volunteer subjects, we had different subject numbers in different sessions, leading to differences in the strength of incentives as well as in the gender composition. We account for these differences among sessions in our econometric analyses, and find that they do not affect our results.
} 
A linear regression with a random effects specification at the subject level also confirms that males take more risk, controlling for the probability of the good state, $\mathrm{p}$, as well as session (see Table 2 for regression results). As expected, individuals also respond to the probability of the good state: the higher this probability, the higher the amount invested in the risky option.

< Insert Table 2 about here >

\subsection{Leadership Decisions:}

Our main result concerns the willingness of men and women to decide for the group. We observe a striking difference between the two genders in this regard: while $86 \%$ of males (68 out of 79) are willing to make the decision for their group, only 55\% of the females (27 out of 49) are willing to do so ( $\mathrm{p}=0.0001$ in a two-sample test of proportions). We first study whether the leadership decisions of males and females correlate with individual risk-taking, captured by the average amount that the subject allocated to the risky option in the 3 individual decisions. Nonparametric tests show that while female "leaders" and "non-leaders" are not significantly different in terms of the average amount of risk they take for themselves, male leaders are individually more risk-taking than male non-leaders, significant at the $10 \%$ level $(\mathrm{p}=0.61$ for females and $\mathrm{p}=0.075$ for males in a Mann-Whitney test). Table 3 presents results from logistic regressions of males' and females' decision to "lead" on individual risk attitudes, controlling for session. Risk attitudes in the individual decision-making task have no significant effect on the females' decision, but has a positive effect for males--that is, males who make riskier decisions for themselves are more likely to choose to decide for the group.

\section{< Insert Table 3 about here >}

\subsection{Group Risk Decisions:}

We now turn to the analysis of how much risk men and women take on behalf of their group, and whether this correlates with their leadership decisions. Table 4 presents summary statistics for the amount allocated to the risky option for the group for each $\mathrm{p}$, broken down by gender as well 
as the leadership decision. For comparison, we also report the amount of risk taken in the individual decision task by these subgroups.

\section{< Insert Table 4 about here >}

A first question to answer here is whether females who would like to decide on behalf of their group take a higher or lower amount of risk for the group than males who would like to do so. A Mann-Whitney test shows that self-selected female leaders take less risk than male leaders on average $(\mathrm{p}=0.015){ }^{8}$ Another interesting comparison concerns women who are willing to be leaders versus women who would prefer not to make this decision. We find that females who choose to lead act no differently in terms of group risk-taking than females who do not ( $\mathrm{p}=0.832$, Mann-Whitney test). In contrast, there is a significant difference between leader and non-leader males: men who are willing to decide for their group take significantly more risk on behalf of the group than males who are not $(\mathrm{p}=0.0134)$. These results are consonant with our previous results on the correlation of individual risk-taking and the leadership decision for males and females.

Our within-subject design also allows us to explore whether individuals take more risk in the group context, as compared to their choices in the individual risk task. Given the value of $p$, we see that roughly $35 \%$ (14\%) of the time subjects allocate more (less) money to the risky option when they decide alone. On the other hand, subjects make the same allocation decision for themselves and for the group around $51 \%$ of the time. The average amount allocated to the risky option when deciding for the group is significantly lower than in the case where subjects decide for themselves alone (Wilcoxon matched-pairs signed-rank test, p-value $<0.000$ ). That is, we find evidence for "cautious shifts".

\section{$<$ Insert Figure 1 about here >}

Figure 1 summarizes the mean amount of risk chosen for the group and the risk chosen for the self, broken down by gender and the decision to lead. The figure shows that men who prefer not to lead would register a sharp decline in the amount of risk they are willing to take, if

\footnotetext{
${ }^{8} \mathrm{We}$ calculate the average amount allocated to the risky option by each subject in the 3 group decision tasks, and compare this across our subgroups.
} 
they were to decide for the group. That is, the tendency to engage in cautious shift is strongest for this subgroup. In order to understand the determinants of group risk decisions better, we also perform a linear regression analysis on subjects' risk allocation for the group using a randomeffects specification. Our regressors are the following: the amount of risk taken individually, dummies for the probability of the good state, a dummy for being male, a dummy for the decision to lead ( 1 if the subject wants to lead the group, 0 otherwise) and an interaction term between gender and leadership, as well as controls for session. Table 5 reports the results. The significant positive coefficient of individual risk indicates that the level of risk taken on behalf of the group is higher for subjects who made riskier choices for themselves. Subjects also respond to the probability of the good state when deciding for the group, taking significantly more risk as this probability increases. Interestingly, for female subjects, the decision to lead does not affect the risk level chosen for the group, as evidenced by the insignificant coefficient for the decision to lead, confirming the results of the non-parametric tests reported earlier. ${ }^{9}$ Contrary to this, the negative and significant coefficient for being male, together with the positive and significant coefficient for the interaction term, implies that male subjects who do not want to lead decide more cautiously for the group compared to leader males. ${ }^{10}$

< Insert Table 5 about here >

\subsection{The Effects of Personality Measures on Risk-Taking and Leadership}

We now explore whether risk-taking and leadership decisions are predicted by the five factors identified by the Neo-FF-TR personality test: openness, conscientiousness, extroversion, agreeableness, and neuroticism. For this, we use data from 117 subjects that completed the personality test. We first look at whether the five personality traits predict individual risk

\footnotetext{
${ }^{9}$ Due to our specification of the dummy variables, the reference group in the regression is female subjects who do not want to lead.

${ }^{10}$ One potential issue in our risk comparisons between leaders and non-leaders might be that non-leaders face less strong monetary incentives, since their decisions have a lower probability of being implemented for the group. One indirect way of understanding whether this is likely to be an important concern is to check whether sessions with different numbers of subjects (and thus incentives of different strength) lead to different risk-taking behavior on average. Our analyses indicate that such incentive effects do not effect individual risk-taking significantly, suggesting that our comparisons of leaders and non-leaders are also unlikely to be affected by incentive differences between the two groups.
} 
attitudes. In order to do this, we run regressions of the average amount allocated to the risky option in the individual decision-task on the five personality traits separately for males and females, adding session dummies as before. While none of the factors is significant for men, we find that neuroticism is negatively correlated with individual risk-taking for women (significant at the 5\% level). This result is consistent with personality studies that have associated neuroticism with lower risk-taking (e.g. Lauriola \& Levin (2001)).

\section{< Insert Table 6 about here >}

Table 6 displays the mean scores for the 5 traits, broken by gender and the decision to lead. Female leaders score higher on openness and lower on conscientiousness, whereas male leaders score higher on openness, lower on conscientiousness, and lower on agreeableness. If we run regressions of the decision to lead on personality traits as well as risk attitudes separately for males and females, we confirm that male leaders are significantly more "open" and "agreeable" than non-leader males (see Table 7). The finding about low agreeableness could be consonant with leadership studies that have shown male leaders to have a less democratic style (Eagly and Johnson, 1990), although our group decision task is not focused on measuring this. While none of the traits reach statistical significance for women, women leaders tend to be more open just as in the case of males, and also less conscientious, as evidenced by the signs of the respective coefficients. These results suggest that while openness can be a general trait of leader types, being less agreeable is likely to be a determinant of leadership for men but not for women. A regression that uses the pooled data confirms that openness to experience increases the likelihood of deciding for the group (Table 7, column 3).

\section{< Insert Table 7 about here >}

\section{Discussion and Concluding Remarks:}

Many economic decisions are made in group contexts, where the choices of an individual determine the payoffs of everyone in the group. In addition, these decisions often involve a risk component, with gains and losses possible for everyone including the decision-maker. In many 
cases, taking on the responsibility of such decision-making is at least partially voluntary, with some people being more willing to make or influence the group decision. However, people also sometimes involuntarily find themselves in the position of deciding on behalf of others who are socially tied to themselves. Given this, it is important to study (1) who rises to the occasion of being a "leader" that makes risky decisions on behalf of others in groups, (2) how self-selected leaders differ from appointed leaders in their actual decisions, (3) how decisions made in the group context compare to cases where individuals decide for themselves in isolation.

This paper provides a first experimental study of these issues, paying special attention to the relationship between gender and the willingness to make risky decisions that affect others. Our results raise some interesting points. The main result is that more women than men would rather not take the responsibility of making a risky decision that affects others, even when their own payoffs are at stake too. Since many decisions in top positions in the workplace involve the responsibility of deciding for others under uncertainty, this relative unwillingness of women to make such decisions can be an important reason why men are more likely to be found in leader positions in the workplace and in social life. ${ }^{11}$

In terms of the group decisions of self-selected leaders, we find that female leaders will take less risk than male leaders when they decide for their group, controlling for their individual risk attitudes. Therefore, if leadership decisions are endogenous in reality, we expect to see fewer female-led groups in domains involving risk over monetary payoffs, and these groups to act more cautiously than male-led groups. Our design also allows us to observe how individuals who would rather not be leaders would act, if they were put in the position of making the decision for others. Leader men take significantly more risk than non-leader men for their group, whereas we do not find a difference in group decisions between women who want to lead and women who do not. Leader and non-leader women do not seem to differ in their individual risk attitudes either. This suggests that some other aspect of preferences might be behind women's leadership choices.

While our personality data show that male leaders are significantly more open to experience and less agreeable than male non-leaders, our sample size for women is not large

\footnotetext{
${ }^{11}$ In this sense, our gender-leadership choice result is reminiscent of the experimental finding that women tend to shy away from competition, which is another self-selection result that is frequently cited as a strong explanation for the relative absence of women from top managerial positions (Gneezy and Rustichini (2004), Niederle and Vesterlund (2007), Gneezy, Leonard and List (2009)). Women have also been found to respond to competitive incentive schemes less favorably (e.g. Gneezy, Niederle and Rustichini (2003)).
} 
enough to make a conclusive point on personality traits and leadership. Based on differences in means, however, being less open to experience and being more conscientious emerge as two potential traits that could possibly affect the aversion to taking responsibility for the group among women. Alternatively, leadership might simply be an unimportant decision for females, making them indifferent, with about half of the sample choosing to lead and half not. Further research is needed in order to disentangle these hypotheses and to shed more light on the reasons behind the gender difference in the decision to lead.

In general, the decision to lead could come from a desire for controlling others, or alternatively, an aversion to leaving the control to others. Similarly, the decision not to lead in such a risky context could be based on a specific aversion to being responsible for the possible loss of others, or simply an indifference to relinquishing control. The former explanation also ties in to uncertainty about the preferences of others in the group: a fruitful direction for further research lies, for example, in analyzing leadership decisions when the gender composition and/or the risk preferences of the group members are known, or when individuals are able to pass the information about their own preferences to other group members and let them decide. 


\section{References}

Adler, N. J. and Izraeli, D. N., 1994. Competitive frontiers: Women managers in a global economy. Cambridge, MA: Blackwell.

Baker II, R.J. and Laury, S. and Williams, A.W., 2007. Comparing small-group and individual behavior in lottery-choice experiments. Mimeo.

Baltussen, G. and Post, T. and Van den Assem, M.J. and Wakker, P.P., 2010. Random incentive systems in a dynamic choice experiment. Mimeo.

Blau, F.D. and Ferber, M. and Winkler, A., 2002. The Economics of Women, Men and Work, 4th edition. Englewood Cliffs, NJ: Prentice Hall.

Borghans, L. and Duckworth, A. and Heckman, J.J. and Ter Weel, B., 2008. The economics and psychology of personality traits. Mimeo.

Chakravarty, S. and Harrison, G.W. and Haruvy, E.E. and Rutström, E.E., 2005. Are you risk averse over other people's money. Mimeo.

Costa, P.T.Jr. and McCrae, R.R., 1992. Revised NEO Personality Inventory (NEO-PI-R) and NEO Five-Factor Inventory (NEO-FFI) manual. Odessa, FL: Psychological Assessment Resources.

Croson, R. and Gneezy, U., 2009. Gender differences in preferences. Journal of Economic Literature 47, 448-474.

Daruvala, D., 2007. Gender, risk and stereotypes. Journal of Risk and Uncertainty. 35, 265-283.

Davis, J.H., 1992. Some compelling intuitions about group consensus decisions, theoretical and empirical research, and interpersonal aggregation phenomena: Selected examples 1950-1990. Organizational Behavior and Human Decision Processes 52, 3-38

Eagly, A.H. and Karau, S.J., 2002. Role congruity theory of prejudice toward female leaders, Psychological Review 109, 573-597.

Eagly, A.H. and Johnson, B.T., 1990. Gender and leadership style: A meta-analysis, Psychological Bulletin 108. 233-256. 
Eckel, C.C., and Grossman, P.J., 2008. Men, Women, and Risk Aversion: Experimental Evidence. In C. Plott and V. Smith (Eds). Handbook of Experimental Economics Results, 10611073. New York: Elsevier.

Gneezy, U. and Potters, J., 1997. An experiment on risk taking and evaluation periods, Quarterly Journal of Economics 112. 631-645.

Gneezy, U., and Rustichini, A., 2004. Executives versus Teachers: Gender, Competition and Self-Selection. Unpublished paper.

Gneezy, U. and Niederle, M. and Rustichini, A., 2003. Performance in competitive environments: Gender differences, Quarterly Journal of Economics 118(3), 1049- 1074.

Gneezy, U. and Leonard, K.L. and List, J.A., 2009. Gender Differences in Competition: Evidence from a Matrilineal and a Patriarchal Society, Econometrica 77, 1637-1664. 645.

Gülgoz, S., 2002. Five Factor Model and NEO-PI-R in Turkey. In R. R. McCrae \& J. Allik (Eds.), The Five-Factor Model of Personality Across Cultures (175-196). New York: Kluwer Academic / Plenum Publishers.

Harrison, G.W. and Lau, M.I. and Rutström, E.E. and Tarazona-Gómez, M., 2005. Preferences over social risk. Mimeo.

Lauriola, M. and Levin, I.P., 2001. Personality traits and risky decision-making in a controlled experimental task: An exploratory study. Personality and Individual Differences 2, 215-226.

Masclet, D. and Colombier, N. and Denant-Boemont, L. and Lohéac, Y., 2009. Group and individual risk preferences: A lottery-choice experiment with self-employed and salaried workers. Journal of Economic Behavior and Organization 70, 470-484.

Melkas, H., \& Anker, R.,1997. Occupational segregation by sex in Nordic countries: An empirical investigation. International Labour Review 136, 341-363.

Niederle, M. and Vesterlund, L., 2007. Do women shy away from competition? Do men compete too much?. The Quarterly Journal of Economics 122. 1067-1101

Shupp, R.S. and Williams, A.W., 2008. Risk preference differentials of small groups and individuals. The Economic Journal 118, 258-283. 
Figure 1: Individual and Group Risk by Gender and Leadership

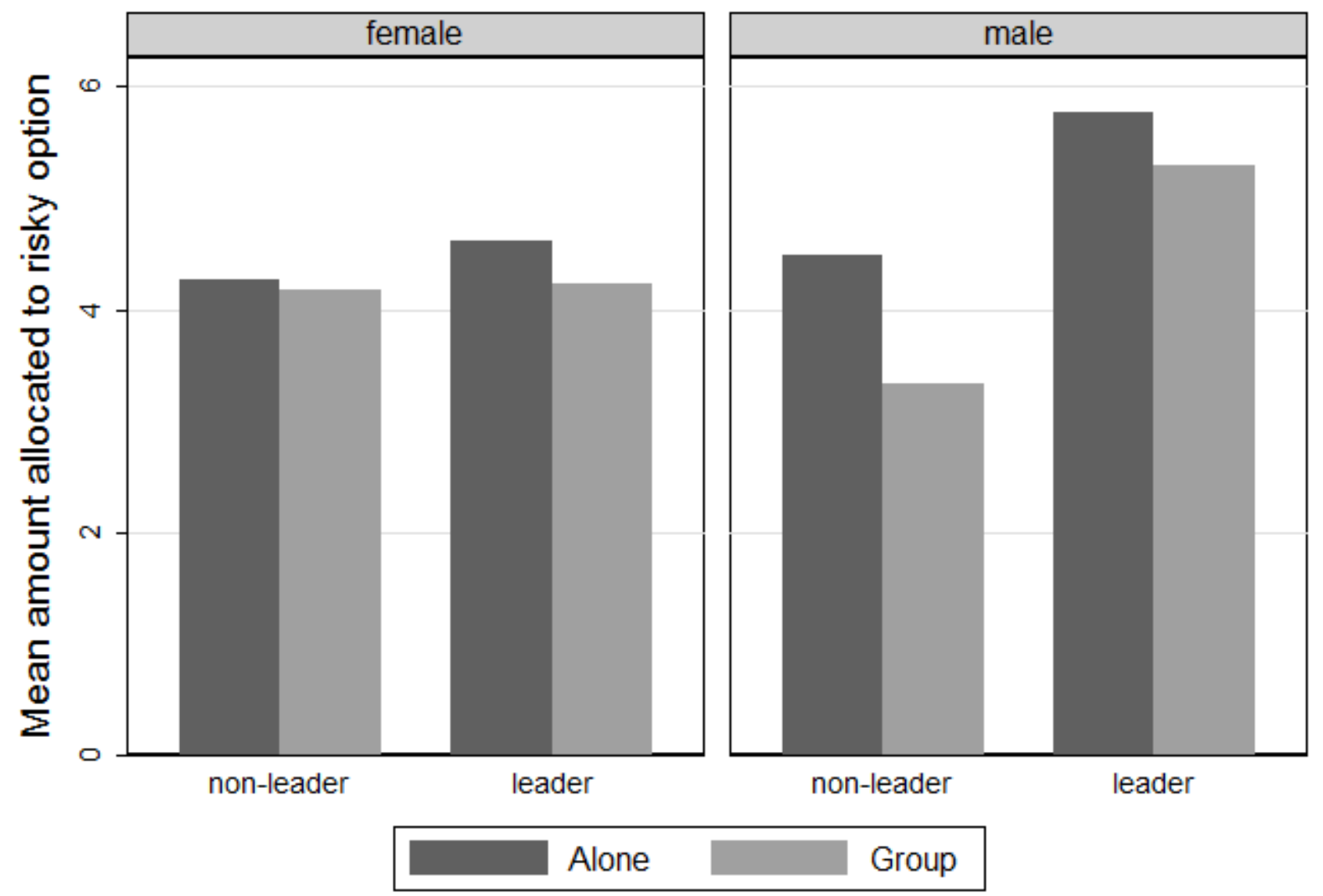


Table 1: Amount Allocated to the Risky Option by Men and Women in the Individual Decision Task

\begin{tabular}{ccc} 
& Female & Male \\
\hline $\mathrm{p}=1.5$ & 3.490 & 3.973 \\
& $(2.582)$ & $(2.964)$ \\
$\mathrm{p}=2$ & 4.459 & 5.568 \\
& $(1.957)$ & $(2.373)$ \\
$\mathrm{p}=2.5$ & 5.429 & 7.232 \\
& $(2.150)$ & $(2.587)$ \\
\hline $\mathrm{N}$ & 49 & 79 \\
\hline
\end{tabular}

Note: Means reported, standard errors in parentheses. 
Table 2: Determinants of Amount Allocated to the Risky Option

\begin{tabular}{lc}
\hline Male & $\begin{array}{c}1.121^{* * * *} \\
(.365)\end{array}$ \\
$\mathrm{p}=2$ & $1.355^{* * *}$ \\
& $(.246)$ \\
$\mathrm{p}=2.5$ & $2.753^{* * *}$ \\
& $(.246)$ \\
Controls for & Yes \\
session & \\
\hline $\mathrm{N}$ & 384 \\
$R^{2}$ & 0.20
\end{tabular}

Note: Coefficients reported, standard errors in parentheses. *'s denote significance at levels; *** $\mathrm{p}<0.01,{ }^{* *} \mathrm{p}<0.05, * \mathrm{p}<0.1$. The number of observations for each of the 128 subjects is 3 . A constant is included in all regressions but not reported. 


\section{Table 3: Determinants of the Leadership Decision}

\begin{tabular}{lcc} 
& Female & Male \\
\hline $\begin{array}{l}\text { Average } \\
\begin{array}{l}\text { Individual } \\
\text { Risk }\end{array}\end{array}$ & $\begin{array}{c}0.013 \\
(0.044)\end{array}$ & $\begin{array}{c}0.038^{* *} \\
(0.016)\end{array}$ \\
$\begin{array}{l}\text { Controls for } \\
\text { session }\end{array}$ & Yes & Yes \\
\hline \multicolumn{1}{c}{$R^{2}$} & 0.047 & 0.1198 \\
\multicolumn{1}{c}{$\mathrm{N}$} & 49 & 79
\end{tabular}

Note: Marginal effects reported, standard errors in parentheses. ${ }^{*}$ 's denote significance at levels; $* * * \mathrm{p}<0.01, * * \mathrm{p}<0.05, * \mathrm{p}<0.1$. Sessions effects are controlled but not reported. A constant is included in all regressions but not reported. 
Table 4: Amount Allocated to the Risky Option on Behalf of the Group and Individually

\begin{tabular}{lllll} 
& $\begin{array}{l}\text { Female } \\
\text { Non- Leader }\end{array}$ & $\begin{array}{l}\text { Female } \\
\text { Leader }\end{array}$ & $\begin{array}{l}\text { Male } \\
\text { Non-Leader }\end{array}$ & $\begin{array}{l}\text { Male } \\
\text { Leader }\end{array}$ \\
\hline Group, $\mathrm{p}=1.5$ & $\begin{array}{l}3.114 \\
(2.920)\end{array}$ & $\begin{array}{l}3.148 \\
(2.413)\end{array}$ & $\begin{array}{l}1.454 \\
(2.018)\end{array}$ & $\begin{array}{l}3.603 \\
(2.905)\end{array}$ \\
Group, $\mathrm{p}=2$ & 4.25 & 4.370 & 3.727 & 5.331 \\
& $(2.203)$ & $(2.133)$ & $(2.760)$ & $(2.311)$ \\
Group, $\mathrm{p}=2.5$ & 5.160 & 5.148 & 4.818 & 6.940 \\
& $(2.670)$ & $(1.834)$ & $(3.736)$ & $(2.552)$ \\
Individual, $\mathrm{p}=1.5$ & 2.909 & 3.962 & 3.090 & 4.117 \\
& $(2.724)$ & $(2.410)$ & $(2.586)$ & $(3.014)$ \\
Individual, $\mathrm{p}=2$ & $\begin{array}{l}4.455 \\
(2.063)\end{array}$ & $\begin{array}{l}4.463 \\
(1.906)\end{array}$ & $\begin{array}{l}4.545 \\
(2.381)\end{array}$ & $\begin{array}{l}5.734 \\
(2.347)\end{array}$ \\
Individual, $\mathrm{p}=2.5$ & 5.455 & 5.407 & 5.818 & 7.462 \\
& $(2.405)$ & $(1.966)$ & $(3.628)$ & $(2.334)$ \\
\hline $\mathrm{N}$ & 22 & 27 & 11 & 68
\end{tabular}

Note: Means reported, standard errors in parentheses. 
Table 5: Determinants of Amount Allocated to the Risky Option on behalf of the Group

\begin{tabular}{lc}
\hline Individual Risk & $\begin{array}{c}0.668 * * * \\
(.037)\end{array}$ \\
$\mathrm{p}=2$ & $0.659 * * *$ \\
& $(.200)$ \\
$\mathrm{p}=2.5$ & $0.993 * * *$ \\
& $(0.220)$ \\
Leader & -0.048 \\
& $(0.363)$ \\
Male & $-1.039 * *$ \\
& $(0.464)$ \\
Male Leader & $1.243 * *$ \\
& $(0.546)$ \\
Controls for session & Yes \\
\hline \multirow{2}{*}{$R^{2}$} & 0.62 \\
$\mathrm{~N}$ & 384
\end{tabular}

Note: Coefficients reported, standard errors in parentheses. ${ }^{*}$ 's denote significance at levels; $* * *$ $\mathrm{p}<0.01, * * \mathrm{p}<0.05, * \mathrm{p}<0.1$. 
Table 6: Personality Scores by Gender and Leadership

\begin{tabular}{lcccc} 
& $\begin{array}{c}\text { Female } \\
\text { non- } \\
\text { leader }\end{array}$ & $\begin{array}{c}\text { Female } \\
\text { leader }\end{array}$ & $\begin{array}{c}\text { Male } \\
\text { non-leader }\end{array}$ & $\begin{array}{c}\text { Male } \\
\text { leader }\end{array}$ \\
\hline Neuroticism & 53.334 & 53.565 & 44.104 & 46.861 \\
& $(8.511)$ & $(10.869)$ & $(8.572)$ & $(10.743)$ \\
Extroversion & 53.665 & 53.806 & 52.270 & 51.060 \\
& $(10.952)$ & $(9.618)$ & $(9.566)$ & $(9.201)$ \\
Openness & 48.714 & 52.017 & 44.832 & 51.410 \\
& $(8.721)$ & $(10.705)$ & $(11.925)$ & $(10.799)$ \\
Agreeableness & 48.863 & 49.328 & 52.528 & 45.248 \\
& $(11.779)$ & $(7.628)$ & $(10.020)$ & $(10.448)$ \\
Conscientiousness & 52.033 & 48.630 & 52.117 & 48.928 \\
& $(11.171)$ & $(9.102)$ & $(13.631)$ & $(9.896)$ \\
\hline \multirow{2}{*}{$\mathrm{N}$} & 21 & 22 & 11 & 63
\end{tabular}

Note: Means reported, standard errors in parentheses. Possible scores for each trait range between 0 and 100 . 


\section{Table 7: The Effects of Personality on Leadership}

\begin{tabular}{llll} 
& Females & Males & Pooled \\
\hline Average & .0570 & $0.029^{*}$ & $0.045^{* *}$ \\
Individual Risk & $(0.056)$ & $(0.015)$ & $(0.218)$ \\
Male & & - & $0.318^{* * *}$ \\
Neuroticism & 0.435 & & $(0.100)$ \\
& $(1.027)$ & 0.089 & 0.391 \\
Extroversion & -0.292 & $(0.270)$ & $(0.415)$ \\
& $(0.906)$ & -0.287 & -0.326 \\
Openness & 0.939 & $(0.348)$ & $(0.447)$ \\
& $(0.958)$ & $0.459 *$ & $0.758^{*}$ \\
Agreeableness & -0.009 & $(0.259)$ & $(0.403)$ \\
& $(0.907)$ & $-0.538^{*}$ & -0.518 \\
Conscientiousness & -1.098 & $(0.277)$ & $(0.408)$ \\
& $(0.889)$ & -0.071 & -0.508 \\
Controls for & Yes & $(0.249)$ & $(0.396)$ \\
session & & Yes & Yes \\
\hline$R^{2}$ & 0.078 & & 0.147 \\
$\mathrm{~N}$ & 43 & 0.238 & 117 \\
& & 74 & \\
\hline
\end{tabular}

Note: Marginal effects reported, standard errors in parentheses. In the regression, personality scores were normalized to take values between 0 and 1 . 


\section{APPENDIX}

\section{Instructions $^{12}$}

Welcome to this study on decision-making. The experiment is going to consist of two parts. There are going to be 3 decisions in each part of the experiment. That is, you are going to make 6 decisions in total. Only one of these six decisions will be used for determining payments from the experiment. This decision will be randomly selected at the end of the experiment, with the roll of a six-sided die. Every decision is equally likely to be selected, so please make all your decisions carefully. Your decisions will be recorded by your unique subject id, and you will be paid privately, in cash. You will all be paid 5 TL for your participation. In addition, at the end of the experiment, we will randomly select 5 participants and they will earn money according to the choices they made in the selected decision (out of the six decisions).

We will now start explaining the decision tasks in the first part. Please listen carefully. If you have a question at any point during the experiment, please raise your hand. An experimenter will come and assist you.

\section{Part 1:}

There are going to be 3 decisions in this part of the experiment. Remember that every decision has an equal chance of being selected for payment.

In each decision, you are going to be asked how you would like to allocate 10 TL between a "risky option" and a "safe option". The amount you put in the safe option remains as it is. Your earnings from the amount you put in the risky option depends on chance. A coin will be flipped-if it comes heads, your earnings from the risky option will be zero. If it comes tails, your earnings from the risky option will be $\mathrm{p}$ times the amount you put in that option. The value of $\mathrm{p}$ is written in the relevant box for each decision on your decision sheets, and it is greater than 1 . Your total earnings from the decision is the sum of your earnings from the safe option and your earnings from the risky option.

Now, please write your decisions on your sheets.

\section{Part 2:}

There are going to be 3 decisions in this part of the experiment. Remember that every decision has an equal chance of being selected for payment.

\footnotetext{
12 The original instructions were in Turkish.
} 
If a decision in this part is selected for payment, 5 people will be randomly selected to form a group, and each group member will get the same payoff, according to the "group decision". The group decision, in turn, is made by a single member. Among the 5 group members, a single one will be selected as the decision-maker and his/her decision will count, to determine the payoffs of everyone in the group. You will not get to know the identities or decisions of your group members. Similarly, other members will not get to know your identity and your decisions.

First, you will be asked whether you want to decide on behalf of your group or not. You will mark your answer as yes/no on your decision sheets.

Based on the answers of the group members, we select whose decision counts for the group in the following way:

- If you were the only person in your group who said yes to the question of whether you want to be the decision-maker, then your decision will count.

- If more than one person in your group said yes, then we will randomly select one among those, and the decision of the selected person will count.

- If none of your group members (including you) wanted to decide for the group, we will again randomly select one among the 5 people, and the decision of the selected person will count.

After saying yes/no to the question of if you want to decide, you will be asked how to allocate 10 TL between a "risky option" and a "safe option" as in Part 1 on behalf of your group, in case your decision counts as the group decision. You will make this decision regardless of whether you said yes/no. Your decision will determine everyone's payoffs in your group if you are selected as the decision-maker, according to the procedures described above.

\section{Sample Decision from the Decision Sheet for Part 1:}

\section{Decision 1:}

Please state how you would like to divide the 10 TL among the Safe Option and Risky Option

\begin{tabular}{|c|c|}
\hline $\begin{array}{c}\text { Safe Option (the money you put here } \\
\text { remains as it is) }\end{array}$ & $\begin{array}{c}\text { Risky Option }(\mathrm{p}=1.5) \\
\text { (if heads, the money you put here will be } \\
\text { multiplied with 1.5, if tails, it will drop to } \\
\text { zero) }\end{array}$ \\
\hline & \\
\hline
\end{tabular}

